\title{
Notas sobre a política de monitoração eletrônica no estado do Rio de Janeiro ${ }^{1}$
}

\author{
Notes on the electronic monitoring policy \\ in the state of Rio de Janeiro
}

\author{
Thiago Bottino ${ }^{2}$ \\ Professor adjunto e coordenador do curso de Direito \\ da Fundação Getúlio Vargas - Rio de Janeiro/RJ \\ Doutor em Direito PUC-Rio e Pós-Doutor Columbia Law School \\ thiago.bottino@fgv.br \\ lattes.cnpq.br/3134056986747443 \\ orcid.org/0000-0003-0557-5412
}

Fernanda Prates ${ }^{3}$

Professora substituta na Universidade Federal do Rio de Janeiro - Rio de Janeiro/RJ

Pós-doutoranda na Fundação Getúlio Vargas Rio de Janeiro/RJ. Doutora Universidade de Montréal.

fernanda.fraga@fgv.br

lattes.cnpq.br/7503304222812900

D. orcid.org/0000-0001-6420-6778

1 A pesquisa foi realizada como parte do estágio de pós-doutorado da autora Fernanda Prates realizado na Fundação Getulio Vargas - RJ e financiado pela Capes, através do Programa Nacional de Pós-Doutorado (PNPD), sob a supervisão do autor Thiago Bottino, seu orientador de estágio. Participaram da coleta dos dados que embasaram a pesquisa alunos de graduação em direito que desenvolviam atividade de iniciação científica da Fundação Getulio Vargas (Daniel Alves Pereira, Gustavo Schreiber Britto, Lucas Florençano de Castro Monteiro e Matheus Eleon Peixoto Figueiredo Vieira) e da Universidade Federal do Estado do Rio de Janeiro (Daniella Teixeira e Marcelo Engelke Muniz), a quem os autores agradecem.

2 Pós-Doutor em Direito pela Columbia Law School (2014). Doutor (2008) e Mestre (2004) em Direito Constitucional pela PUC-Rio. Professor Adjunto e Coordenador de Graduação da FGV Direito Rio. Professor Adjunto da Universidade Federal do Estado do Rio de Janeiro (UNIRIO). Membro efetivo da Comissão Permanente de Direito Penal do IAB.

3 Pós-doutoranda em Direito (FGV Direito Rio), Pós-doutora em Criminologia (Universidade de Ottawa, Canada) e Doutora em Criminologia (Universidade de Montréal, Canada). Professora substituta de Direito Penal e Criminologia da Faculdade Nacional de Direito - UFRJ. 
Resumo: Partindo da análise de decisões proferidas ao longo de um ano (2015) pelas Câmaras Criminais do Tribunal de Justiça do Rio de Janeiro, buscou-se examinar de que forma a tecnologia da monitoração eletrônica vem sendo aplicada pelo Poder Judiciário. O presente artigo apresenta os resultados desta análise, discutindo (1) a questão da limitação do uso desta ferramenta como alternativa à prisão cautelar e (2) as problemáticas ligadas à sua aplicação pelo Tribunal no âmbito da execução penal.

Palavras-chave: Monitoração eletrônica; Prisão cautelar; Execução penal; Pesquisa empírica; Tribunal de Justiça do Rio de Janeiro; Disparidade de tratamento.

ABSTRACT: Through the analysis of the decisions passed by the Criminal Court of Justice of Rio de Janeiro, we examine how the Judiciary has adopted electronic monitoring technology. This article discusses (1) the limited use of electronic monitoring as an alternative to pre-trial detention and (2) the problems related to the adoption of electronic monitoring during the course of a sentence.

Key words: Electronic monitoring; Pre-trial detention; Correctional system; Empirical research; Rio de Janeiro State Court of Justice; Sentencing disparity.

SumÁRıo: Introdução; 1. Resultados; 1.1. A monitoração eletrônica como alternativa à prisão cautelar; 1.2. A monitoração eletrônica no âmbito da execução penal; 1.2.1. As decisões do Tribunal de Justiça; Considerações finais; Referências.

\section{INTRODUÇÃO}

Criada nos Estados Unidos na década de 1960, a tecnologia de monitoração eletrônica se popularizou nos anos 1980, tendo sido gradualmente adotada em vários países, tais como Inglaterra, África do Sul, Alemanha, Bélgica, Canadá, China e Portugal (Japiassú e Macedo, 2008, p. 15; Oliveira e Ghiringhelli, 2011, pp. 100-103). As finalidades do emprego desta tecnologia seriam as seguintes: (1) a detenção, asse- 
gurando a permanência do indivíduo em determinado lugar; (2) a restrição, garantindo que o indivíduo não frequente certos locais ou não se aproxime de certas pessoas; e, finalmente, (3) a vigilância, permitindo o controle e acompanhamento de todos os atos praticados pelo monitorado de forma irrestrita (Mariath, 2009, pp. 4-5; Duarte e Menezes, p.80; Fonseca, 2012, p. 75).

De modo geral, podemos identificar três objetivos principais que justificaram a introdução da monitoração eletrônica em diversos países, quais sejam: (1) o combate à superpopulação carcerária; (2) a diminuição dos encargos com pessoas encarceradas; e, (3) a redução de riscos de reincidência criminal (Campello, 2013, p. 41). Nesse sentido, Iglesia e Parente esclarecem que:

En primer plano, desde una perspectiva prioritariamente pragmática, se sostiene que la vigilancia electrónica contribuye a una disminución de la población carcelaria y a un ahorro de costes ligados a la administración penitenciaria. En segundo lugar (...) el control electrónico evita o reduce la privación de libertad en prisión, por lo que contribuye a favorecer y acelerar el proceso de resocialización del condenado, evitando al mismo tiempo los efectos negativos inherentes la prisionalización ${ }^{4}$. (Iglesia e Parente apud Ministério da Justiça, 2008, p. 15)

A monitoração eletrônica foi inicialmente instituída no Brasil através da Lei $n^{0} 12.258 / 10$, dispondo sobre sua utilização na fase da execução penal nas hipóteses de autorizações de saída temporária, no regime semiaberto e na prisão domiciliar. Ressalte-se, entretanto, que algumas unidades federativas implementaram o uso da monitoração eletrônica antes mesmo da regulamentação legal, podemos citar, por exemplo, o Estado da Paraíba (2007) e de São Paulo (2008) (Campello, 2013, pp. 160-165).

4 "Em primeiro lugar, a partir de uma perspectiva principalmente pragmática, argumenta-se que a vigilância eletrônica contribui para uma redução da população da população carcerária bem como dos custos associados à administração prisional. Em segundo lugar (...) a monitoração eletrônica evita ou reduz a privação de liberdade da prisão, favorecendo e acelerando o processo de ressocialização do condenado, e evitando ao mesmo tempo o os efeitos negativos inerentes ao encarceramento" (Tradução livre). 
Em 2009 o Rio de Janeiro também já havia aprovado lei própria $^{5}$, regulamentando a monitoração eletrônica de apenados no regime aberto e semiaberto, prevendo a possibilidade de vigilância através de bracelete ou tornozeleira, além de "chip subcutâneo". Entretanto, a implementação desta tecnologia no âmbito da justiça penal fluminense só se deu em 2010, com a entrada em vigor da Lei 12.258/10.

Posteriormente, em 2011, foi sancionada a Lei 12.403/2011, aplicando a vigilância eletrônica como medida cautelar diversa da prisão preventiva ${ }^{7}$. Buscava-se com a referida Lei uma redução significativa do número de presos provisórios no País, que representam um dos principais fatores de superlotação penitenciária (Depen, 2015, p.9).

Percebe-se que a tecnologia da monitoração eletrônica constitui uma inovação recente no âmbito do sistema de justiça criminal. Nesse sentido, pouco ainda se sabe sobre a aplicação desta nova ferramenta. Por outro lado, tal análise se mostra fundamental para a avaliação das práticas e formulação de políticas.

Nesse sentido, o presente artigo apresenta os resultados de pesquisa que buscou examinar de que forma a tecnologia da monitoração eletrônica vem sendo entendida e aplicada pelo Tribunal de Justiça do Estado do Rio de Janeiro ${ }^{8}$. Para isso, realizamos uma pesquisa da jurisprudência produzida pelas Câmaras Criminais do Rio de Janeiro acerca do tema. A análise foi feita a partir da palavra chave "monitoração eletrônica" e estipulou-se um recorte temporal de 13 meses, período que iniciado em 01 de janeiro de 2015, com término em 01 de fevereiro

5 Lei Estadual n ${ }^{\circ} 5.530 / 2009$, de autoria da Deputada Estadual Cidinha Campos (PDT/RJ).

6 Tecnologia vedada em alguns países, como a França (Corrêa Junior, 2012, p. 120).

7 A Lei 12.403/11 não regulamentou o monitoramento eletrônico, delegando aos Estados a competência para tanto (Oliveira e Ghiringhelli, 2011, p. 106).

8 Trata-se de uma pesquisa que possui dois eixos de análise, o primeiro destaca as práticas dos atores penais no que diz respeito à monitoração eletrônica e o segundo, que busca examinar a experiência dos indivíduos monitorados e que será objeto de um próximo artigo.

9 Utilizamos a palavra-chave "monitoração" por ser este termo empregado nas duas leis que regulam a matéria (Lei12.258/10 e Lei 12.403/2011). 
de $2016^{10}$. A busca resultou em 687 decisões. Entretanto, após análise mais aprofundada dos julgamentos, eliminamos 387 decisões daquele universo inicial, tendo em vista que as mesmas não tinham como objeto a monitoração eletrônica, apenas faziam referência ao tratar de outras questões. Assim, para fins de análise, a pesquisa contou com um universo de 300 decisões, todas proferidas pelo TJ do Rio de Janeiro.

As decisões foram separadas por Câmara (existem oito Câmaras Criminais no Tribunal de Justiça do Rio de Janeiro) e para cada processo foi criada uma ficha contendo campos padronizados: Número do Processo; Câmara; Tipo de Procedimento; Autor; Pedido Completo; Síntese do Pedido; Decisão e Fundamentação da Decisão. Concluindo a análise vertical de cada Câmara, era produzido um relatório de análise vertical por Câmara indicando os resultados de cada órgão colegiado (p.ex. padrão de decisão da câmara, fundamentos recorrentes, discussões regulares etc.). Finda a análise vertical, procedeu-se à análise horizontal das Câmaras (análise cruzada), buscando identificar o padrão de decisão do Tribunal de Justiça através do exame das similitudes e diferenças das decisões proferidas pelas Câmaras do TJ/RJ. Apresentaremos a seguir os resultados deste estudo.

\section{Resultados}

Os principais resultados do presente estudo podem ser separados em dois grandes tópicos, que serão abordados a seguir. O primeiro diz respeito ao alcance da ferramenta da monitoração eletrônica enquanto instrumento desencarcerador, especialmente no que diz respeito a sua utilização como alternativa à prisão cautelar. No segundo tópico delimitamos nossa análise à monitoração no âmbito da execução penal, trazendo à tona determinadas problemáticas ligadas à sua aplicação.

10 O recorte de tempo foi definido como sendo o período de um ano imediatamente anterior ao início da pesquisa. Devido à exiguidade de tempo para a realização da pesquisa (a fim de coincidir com o período de pós-doutorado da segunda autora, bem como dos alunos bolsistas de iniciação científica) e a grande quantidade de julgados sobre o tema, consideramos que o recorte de um ano seria adequado. 


\subsection{A MONITORAÇÃO ELETRÔNICA COMO ALTERNATIVA À PRISÃO CAUTELAR}

Conforme dito anteriormente, analisaremos aqui a implementação da política de monitoração eletrônica, tendo como foco os objetivos pretendidos com sua adoção pelo legislador. Estariam os desembargadores aproveitando eficazmente o potencial desencarcerador dessa nova tecnologia? Em que medida essa ferramenta é empregada, por exemplo, como alternativa à prisão preventiva? Enfim, qual destino dado a essa tecnologia pelo Tribunal de Justiça do Rio de Janeiro. O gráfico abaixo apresenta algumas respostas a estas indagações.

Analisando a natureza dos procedimentos foi possível observar que dos 300 casos identificados, pelo menos 72,76\% dizem respeito a processos em fase de execução da pena ${ }^{11}$, indicando que o debate da monitoração eletrônica como medida cautelar alternativa à prisão ainda se apresenta bastante limitado, apesar desta tecnologia ter sido introduzida em nosso ordenamento jurídico há mais de cinco anos.

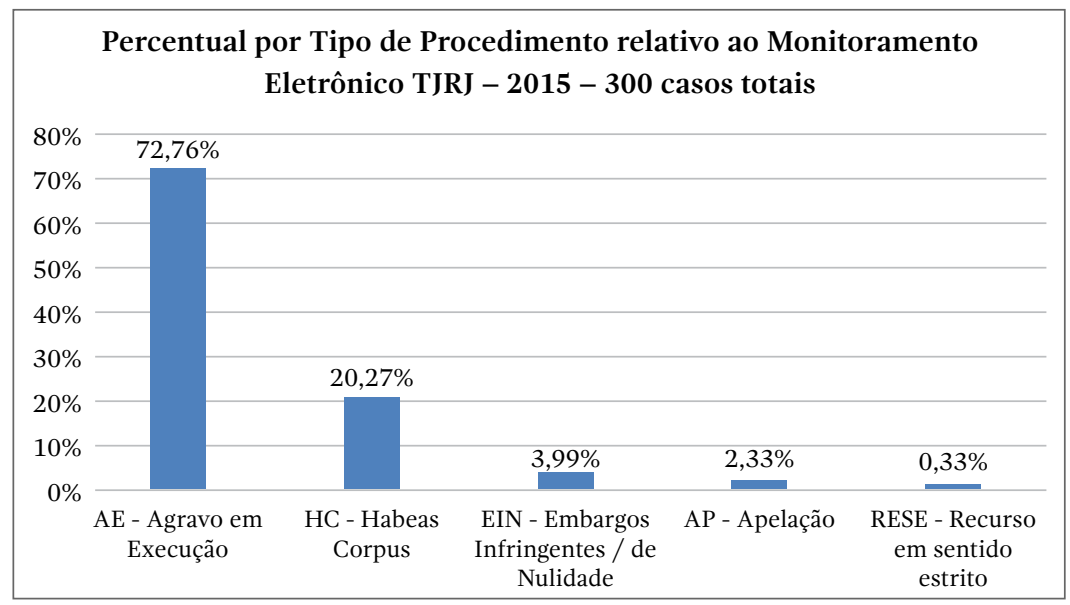

GráfICo 1. Natureza dos Procedimentos. Gráfico que demonstra o percentual de cada tipo de procedimento.

11 Essa afirmação decorre do fato de que o agravo em execução só pode ser manejado durante a fase de execução da pena. Mas o percentual pode ser maior, dado que outros instrumentos processuais (habeas corpus, apelação, recurso em sentido estrito e embargos) podem ser utilizados tanto na fase de execução como na fase de conhecimento. 
A baixa representatividade da monitoração eletrônica enquanto mecanismo desencarcerador no Estado do Rio de Janeiro acompanha uma tendência nacional. Em recente relatório publicado pelo Ministério da Justiça (primeiro diagnóstico nacional sobre a utilização da monitoração eletrônica), vemos que em mais de $86 \%$ dos casos o sistema de monitoração é utilizado na fase de execução da pena, ou seja, em indivíduos que já foram condenados, sendo muito pouco empregada em casos de medidas protetivas de urgência (p. ex. Lei Maria da Penha) ou medidas cautelares diversas da prisão (Ministério da Justiça). Segundo o relatório, dos 18.172 monitorados no país, apenas 1.450 pessoas estão cumprindo medidas cautelares diversas da prisão. No Rio de Janeiro, dos 1.436 monitoramentos, apenas 36 se referem a medidas cautelares diferentes da prisão (Ministério da Justiça, 2015, p.10).

Esses dados se tornam especialmente relevantes - e preocupantes - ao serem analisados em conjunto com aqueles relativos ao uso abusivo das prisões provisórias (Ministério da Justiça e IPEA, 2015, pp. 26-29). De acordo com os últimos dados do Levantamento Nacional de Informações Penitenciárias ${ }^{12}$ (Ministério da Justiça, 2014, pp. 14-17), o Brasil possuía, em 2014, a quarta maior população carcerária do mundo - com 622.202 presos - dentre os quais 40,13\% são presos provisórios.

No Rio de Janeiro temos realidade bem representativa do cenário nacional, com 22 presos mil aguardando julgamento, número que representa $44 \%$ de toda a população carcerária do Estado ${ }^{13}$ (Mecanismo Estadual de Prevenção e Combate à Tortura do Rio de Janeiro, 2016, p.10).

Percebe-se que a escassa discussão da monitoração eletrônica como alternativa à prisão no âmbito do Tribunal de Justiça do Rio de Janeiro reflete um movimento no qual essa nova tecnologia parece se consolidar mais como um mecanismo de controle disciplinar utilizado na gestão prisional (Karam, 2007, p. 5) do que como instrumento de uma política de desencarceramento, frustrando assim o objetivo inicial presente na Lei $\mathrm{n}^{0} 12.403 / 11$ de enfretamento ao grande volume pre-

12 Dados de dezembro de 2014.

13 Número total de presos já ultrapassa 50.000 (Mecanismo Estadual de Prevenção e Combate à Tortura do Rio de Janeiro, 2016, p. 10). 
sos provisórios no Brasil. É justamente nesse sentido a conclusão de Campello (2015, p. 24):

O emprego do monitoramento nos casos previstos não apresenta impacto algum no sentido de reduzir a população carcerária ou possibilitar o desencarceramento anunciado por aqueles que defendiam a medida e contribuíram para a sua ratificação. Permitem, ao contrário, o reforço do controle sobre os que já transitam entre o cárcere e sua extensão a céu aberto, supervisionando os fluxos estabelecidos em meio aos seus poros e redimensionando os limites dados pelos muros da prisão-prédio.

\subsection{A MONITORAÇÃO ELETRÔNICA NO ÂMBITO DA EXECUÇ̃̃O PENAL}

Conforme indicado no gráfico anterior, os dois procedimentos mais frequentes no que tange a monitoração eletrônica são os habeas corpus (20,27\%) e os agravos de execução penal (72,76\%), representando, juntos, 93,03\% dos casos identificados.

Em relação aos habeas corpus ${ }^{14}$, cogitou-se inicialmente que essas ações poderiam versar - ao menos em parte - sobre a aplicação da monitoração eletrônica como medida alternativa à prisão cautelar. Entretanto, a análise dos dados indicou que, em quase sua totalidade, os habeas corpus que têm como objeto a monitoração eletrônica dizem respeito à matéria de execução penal. Podemos citar, por exemplo, writs de habeas corpus requerendo o benefício de visita periódica ao lar e a progressão de regime, a expedição de carta de execução de sentença com transferência para unidade prisional compatível com o regime da condenação, bem como a nulidade da decisão que determinou a regressão cautelar para o regime semiaberto baseada em informação de rompimento do dispositivo eletrônico.

É possível notar assim que tais procedimentos funcionam frequentemente como alternativa ao agravo de execução, tendo em vista a urgência do pedido e o alegado excesso de prazo para apreciação do pleito pela autoridade coatora.

\footnotetext{
14 Representando 20,27\% dos casos identificados.
} 
Esses habeas corpus "alternativos" ao agravo em execução se somam aos agravos propriamente ditos, que correspondem à imensa maioria dos procedimentos em curso no Tribunal de Justiça. Entretanto, diferentemente dos habeas corpus - impetrados pela defesa - os agravos de execução são em sua grande maioria interpostos pelo Ministério Público da Vara de Execuções Penais, apresentando como pleito mais frequente o pedido de cassação da decisão de primeira instância que concedeu direito do apenado cumprir pena em prisão albergue domiciliar (PAD), com ou sem monitoração eletrônica.

Na realidade, o pedido sistemático de cassação da concessão de PAD feito pelo Parquet representa de longe a questão mais debatida no Tribunal de Justiça, no que diz respeito à monitoração eletrônica. A figura abaixo ilustra essa proporção:

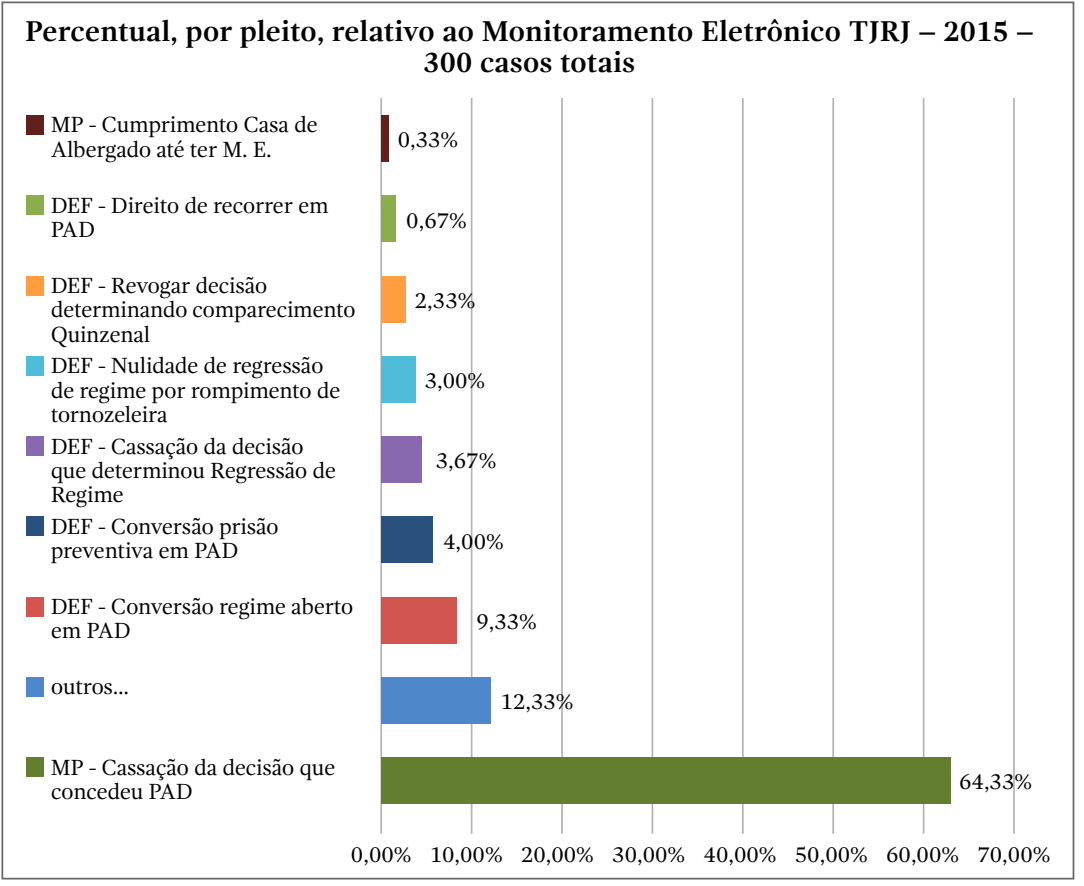

GRÁFICo 2. Natureza dos pedidos

Para uma melhor compreensão das discussões presentes nos referidos pedidos do Ministério Público é necessária uma breve contex- 
tualização acerca do instituto da progressão de regime e de como ele é implementado do Estado do Rio de Janeiro.

Os regimes de cumprimento de pena estão elencados no art. 33 do Código Penal, havendo previsão legal para os regimes fechado, semiaberto e aberto. Fixado pelo juiz sentenciante, a decisão que determina o regime inicial de cumprimento de pena deverá se fundamentar nos requisitos legais objetivos e subjetivos, observando o disposto no artigo 59 do Código Penal ${ }^{15}$.

Em relação aos diferentes tipos de regime, o fechado é aquele cumprido em estabelecimento de segurança máxima ou média (penitenciárias), constituindo, em geral, o regime inicial de pena dos condenados a penas superiores a oito anos de reclusão. Já o regime semiaberto é aquele cumprido em colônias agrícolas, industriais ou estabelecimentos similares (unidades com grau moderado de vigilância). Esse é o regime aplicado ao condenado a uma pena maior que quatro anos e menor que oito anos.

Finalmente, o regime aberto (imposto ao condenado a uma pena igual ou inferior a quatro anos) tem sua execução nas chamadas casas de albergado ou estabelecimento similar. Tendo em vista a menor gravidade dos delitos esse modelo se caracteriza por ser menos rigoroso, dando maior liberdade ao apenado. De fato, baseando-se nas noções da autodisciplina e responsabilidade (Código Penal, art. 36), o regime aberto de cumprimento de pena concede ao apenado liberdade para passar o dia fora da unidade prisional, seja para realização de cursos, formações ou para exercício laborativo. Assim, o apenado deve passar o dia fora da unidade prisional, retornando apenas durante a noite, lá permanecendo também nos seus dias de folga. É necessário que o apenado demonstre que tem capacidade de se ajustar às regras deste regime, aceitando as condições impostas pelo juízo de execução.

O Estado do Rio de Janeiro tem apenas duas casas de albergado para cumprimento de pena em regime aberto, uma masculina

15 Código Penal. Art. 59 - O juiz, atendendo à culpabilidade, aos antecedentes, à conduta social, à personalidade do agente, aos motivos, às circunstâncias e consequências do crime bem como ao comportamento da vítima, estabelecerá, conforme seja necessário e suficiente para reprovação e prevenção do crime. (...) : III - o regime inicial de cumprimento da pena privativa de liberdade. 
e a outra feminina (Casa do Albergado Crispim Ventino e Instituto Penal Oscar Stevenson, respectivamente), ambas situadas na região central da Capital. Além de insuficientes para receber a totalidade dos apenados em regime aberto na região, ambas as unidades apresentam inúmeras precariedades. O relatório de inspeção realizada na Casa do Albergado Crispim Ventino pelo Mecanismo de Prevenção e Combate à Tortura do Rio de Janeiro (MEPCT/RJ) indica, por exemplo, a péssima situação de conservação da unidade, indicando que a mesma possui várias rachaduras, infiltrações, pouca iluminação e ventilação, além de sofrer constantes interrupções no fornecimento de água, o que certamente favorece a insalubridade do ambiente (Mecanismo Estadual de Prevenção e Combate à Tortura do Rio de Janeiro, 2013, pp.23-39).

Em relação ao Instituto Penal Oscar Steveson, em seu relatório temático, o MEPCT/RJ aponta os inúmeros problemas daquela unidade, dentre eles o precário fornecimento de água, a insalubridade ("galeria da unidade com muitas baratas") a superlotação das celas, o uso abusivo das medidas disciplinares ("que provocam até mesmo a perda de emprego"), maus tratos, bem como a proibição de receber visitas (Mecanismo Estadual de Prevenção e Combate à Tortura do Rio de Janeiro, 2013, pp.23-39). Nesse sentido, o relatório conclui afirmando que os

elementos colhidos pelo MEPCT/RJ na visita ao Instituto Penal Oscar Stevenson revelam um sistemático desrespeito à Lei de Execuções Penais (Lei n. ${ }^{0}$ 7.810/84), à Constituição Federal, aos ditames da Convenção de Belém do Pará sobre violência contra a mulher e ao corpus iuris do Direito Internacional dos Direitos Humanos como um todo, reforçando o processo de dupla criminalização o qual vivenciam as mulheres presas em nossa sociedade" (Mecanismo Estadual de Prevenção e Combate à Tortura do Rio de Janeiro, 2016, p. 60).

O legislador deu ao magistrado a discricionariedade de optar - em casos pontuais - pela execução da pena em regime aberto em residência particular, ao invés de estabelecimento prisional. Essa circunstancia está prevista no art. 117 da Lei de Execuções Penais (LEP), que transcrevemos a seguir: 
Art. 117. Somente se admitirá o recolhimento do beneficiário de regime aberto em residência particular quando se tratar de:

I - condenado maior de 70 (setenta) anos;

II - condenado acometido de doença grave;

III - condenada com filho menor ou deficiente físico ou mental;

IV - condenada gestante.

Em virtude dos problemas suscitados anteriormente (poucas unidades, superlotação carcerária, condições precárias dos estabelecimentos), a partir de 2010, a Vara de Execuções Penais do Rio de Janeiro começou a determinar o cumprimento da pena em regime aberto em prisão domiciliar (Pinto, 2014). Entendeu-se que as péssimas condições dos estabelecimentos prisionais de regime aberto ensejariam a interpretação extensiva do citado artigo 117 da LEP. De um modo geral, a concessão de "prisão albergue domiciliar" vinha acompanhada da imposição da monitoração eletrônica, tecnologia que o sistema penitenciário fluminense acabara de implantar ${ }^{16}$. Em decisão de 2013, o Desembargador Marcus Basílio bem descreve essa tendência, identificando-a como uma "virada jurisprudencial":

(...) passo a analisar a correta interpretação a ser aplicada ao art. 117 da Lei de Execução Penal. Durante longo período era comum encontrarmos na doutrina e na jurisprudência afirmações no sentido de que o rol do art. 117 da Lei de Execuções Penais seria taxativo, tendo em vista que se trata de medida excepcional. Todavia, uma evolução na análise do tema fez com que fosse necessário reconhecer hipóteses excepcionais em que a concessão da prisão domiciliar, ainda que não prevista expressamente no texto legal, realizaria de melhor forma a vontade da lei. Uma dessas hipóteses excepcionais é exatamente a do caso concreto, qual seja, inexistência de vagas disponíveis em Casa de Albergado. O inadimplemento por parte do Estado em cumprir as condições que lhe são impostas pela Lei de Execução Penal não pode repercutir de ma-

16 Decisões mais recentes da Vara de execuções penais/RJ concedem prisão albergue domiciliar ainda que desacompanhada da monitoração eletrônica, tendo em vista os problemas enfrentados pelo Estado do RJ no que diz respeito ao pagamento da empresa que realiza o referido serviço. Disponível em: <http:// g1.globo.com/rio-de-janeiro/noticia/2016/09/divida-do-rj-com-fornecedor-de-tornozeleiras-e-de-r-36-milhoes.html>. Acesso em: 11 abr. 2017. 
neira negativa sobre o apenado, impedindo que este exerça um direito subjetivo que lhe é assegurado para sua reinserção social.

(...) A inexistência de estabelecimento adequado para o cumprimento de pena em regime aberto afasta o caráter taxativo da LEP em relação à prisão domiciliar. Ainda que exista Casa de Albergado no Estado do Rio de Janeiro, a sua superlotação equipara a situação à inexistência de estabelecimento adequado para cumprimento de pena no regime.

(...) A superlotação carcerária e as péssimas condições em que se encontram os estabelecimentos de cumprimento de pena em regime aberto foram responsáveis por uma virada jurisprudencial e pela possibilidade de uma interpretação ampliativa do art. 117 da LEP. Os albergues, da maneira como se apresentam, com superlotação e condições de higiene precárias, dificultam a ressocialização buscada pela execução penal. Diante disso, a política da Vara de Execuções Penais do Rio de Janeiro tem se mostrado favorável a uma substituição gradativa das Casas de Albergado por prisões domiciliares com monitoramento eletrônico. (Agravo de execução penal $\mathrm{n}^{\circ}$. 0066580-56.2013.8.19.0000, $1^{\text {a }}$ Câmara Criminal TJ/RJ, Rel. Des. Marcus Basílio).

A referida "virada jurisprudencial" se insere no que parece ser uma tendência mais ampla de politica criminal que pode ser observada, por exemplo, na exposição de motivos da Proposta de Reforma da Lei de Execuções Penais ${ }^{17}$ (Projeto de lei do Senado $n^{0} 513 / 2013^{18}$ ),

17 Disponível em: <http://s.conjur.com.br/dl/anteprojeto-reforma-lep.pdf>. Acesso em: 11 abr. 2017.

18 O Capitulo IV do Titulo IV da LEP passaria a vigorar com a seguinte redação: Do Recolhimento Domiciliar. Art. 95-A. O regime aberto consiste na execução da pena de prestação de serviço à comunidade, cumulada com outra pena restritiva de direitos e com o recolhimento domiciliar. $\S 1^{\circ}$ A pena de prestação de serviço à comunidade será obrigatoriamente executada no período inicial de cumprimento e por tempo não inferior a um terço da pena remanescente. $\S$ $2^{\circ} \mathrm{O}$ recolhimento domiciliar baseia-se na autodisciplina e senso de responsabilidade do condenado, que deverá, sem vigilância direta, trabalhar, frequentar curso ou exercer outra atividade autorizada, permanecendo recolhido nos dias e horários de folga em residência ou em qualquer local destinado à sua moradia habitual. $\S 3^{\circ} \mathrm{O}$ juiz poderá definir a fiscalização por meio da monitoração eletrônica. $\S 4^{\circ}$ Em caso de descumprimento injustificado das condições do regime aberto o condenado regredirá para o regime semiaberto. 
decretando a extinção das Casas de Albergado em território nacional nos seguintes termos:

64. Mantém-se a redação da disciplina concernente às Colônias Agrícolas, Industriais ou similares, destinadas ao cumprimento de pena em regime semiaberto. (...) Por outro lado, é extinta a Casa do Albergado, desde logo inexistente na grande maioria das comarcas do País. Em seu lugar, para cumprimento de pena em regime aberto, passa a se admitir o recolhimento domiciliar cumulado com prestação de serviços à comunidade ou outra pena restritiva de direitos, sempre com possibilidade de fiscalização por monitoração eletrônica.

Apesar da decisão do desembargador Marcos Basílio mencionar que a política da Vara de Execuções Penais do RJ acerca da prisão albergue domiciliar conta com a anuência do próprio Ministério Público "sendo isolados os reclamos do representante do parquet em casos específicos", os elementos coletados ao longo desta pesquisa sugerem uma mudança no posicionamento institucional do Parquet, o qual vem se mostrando extremamente crítico em relação a qualquer interpretação extensiva do artigo 117 da LEP. Analisaremos a seguir os impactos do posicionamento do MP no Tribunal de Justiça do Rio de Janeiro.

Na contramão da referida "virada jurisprudencial", os dados analisados indicam que $64,33 \%$ dos 300 casos analisados ${ }^{19}$ dizem respeito a pedidos feitos pelo Ministério Publico buscando a cassação da decisão que concedeu ao apenado o direito à prisão albergue domiciliar.

Dentre os argumentos mais frequentes, destacamos: (1) o fato de que o apenado não teria cumprido os requisitos do art. 117 da LEP; (2) a existência de vagas disponíveis em Casas de Albergado no Estado do Rio de Janeiro; e, principalmente, (3) a violação ao rol taxativo do art. 117 da LEP, alegando assim um desvirtuamento da PAD, transformando-a em verdadeiro livramento condicional.

\subsubsection{As DECISÕES do TRIBUNAL DE JUSTIÇA}

Conforme mencionado anteriormente, das 300 decisões identificadas, 193 - ou seja, 64,33\% - dizem respeito a recursos do Ministério

19 Número de casos tendo como objeto a monitoração eletrônica. 
Publico visando a cassar a decisão do juízo da VEP concedendo ao sentenciado o direito de cumprir sua pena no regime de prisão albergue domiciliar, seja em razão da superlotação das unidades de regime aberto, de suas condições precárias ou da inexistência de casa de albergado próxima ao local de trabalho/domicilio do apenado.

Buscou-se conhecer o padrão decisório das Câmaras Criminais no TJ/RJ no que diz respeito aos pleitos mencionados. Para tanto, os procedimentos foram divididos em "deferidos" e "indeferidos". Os primeiros se referem aos julgamentos que cassaram a concessão de PAD e determinaram o cumprimento do restante da pena em unidade do regime aberto. Os demais indicam os pedidos que não foram providos, mantendo assim a decisão de $1^{\mathrm{a}}$ instância que havia concedido PAD. Veremos a seguir os fundamentos mais presentes em cada uma das Câmaras.

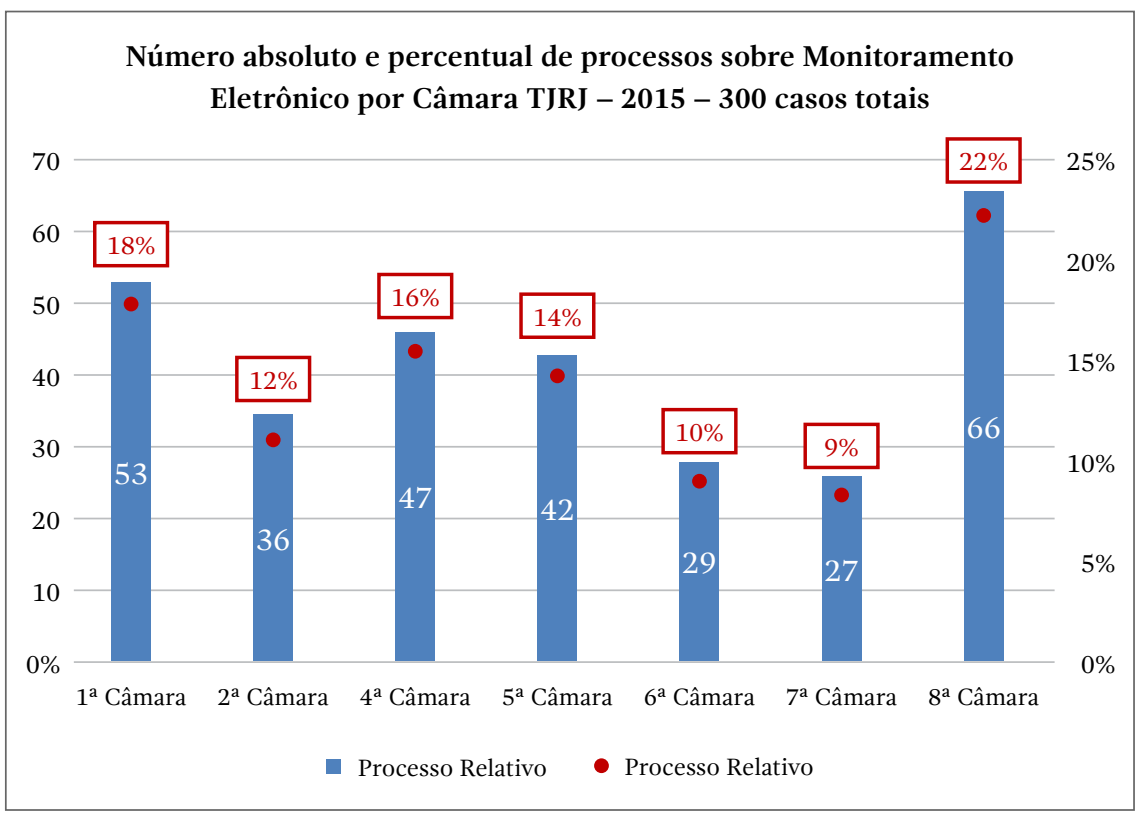

GráfICo 3. Esse gráfico mostra o número total de processos de Monitoramento Eletrônico para cada Câmara ${ }^{20}$, juntamente com o percentual que esse volume representa em relação ao volume total de processos de Monitoramento Eletrônico.

${ }^{20}$ Não houve julgados sobre esse tema na $3^{\mathrm{a}}$ Câmara Criminal durante o período pesquisado. 
A $1^{\text {a }}$ Câmara Criminal julgou 21\% do total de casos observados, tendo deferido $7 \%$ dos pleitos e indeferido 93\%, ou seja, nesta Câmara as decisões que concedem PAD são mantidas integralmente. Em relação às razões de decidir, podemos identificar três argumentos principais utilizados pelos julgadores. Em primeiro lugar, a questão da falta de vagas em casas de albergado, frequentemente identificada como critério de decisão, nos moldes da interpretação extensiva do art. 117 da LEP, como se observa na decisão a seguir:

Progressão para regime aberto. Prisão albergue domiciliar, sob fiscalização por monitoramento eletrônico. Ausência de vagas em casa do albergado. Interpretação extensiva do art. 117 da Lei de Execuções Penais. Princípios da dignidade da pessoa humana e da razoabilidade. Decisão agravada devidamente fundamentada segundo as peculiaridades do caso concreto em consonância com os princípios que regem a execução, em especial a reinserção e ressocialização do apenado. (...) Na presente hipótese, o apenado reside em Vigário Geral, nesta cidade do Rio de Janeiro/RJ e existe instalada apenas uma Casa de Albergado masculina, situada no bairro de Benfica, nesta cidade, mas conforme decisão do juízo da VEP, sem vaga suficiente. (Agravo de execução penal 0065125-85.2015.8.19.0000. Rel. Des. Katia Maria Monnerat. D.J 15/12/2015).

Outro ponto levantado foi a questão da distância entre os locais de cumprimento de pena no regime aberto e a residência ou trabalho do apenado, o que causaria sérios transtornos ao sentenciado:

A prisão domiciliar pode ser concedida quando presente alguma das hipóteses do art. 117 da LEP ou, excepcionalmente, na linha da política do executivo, quando não houver local próximo à residência ou trabalho do apenado para o cumprimento da pena em regime aberto, não sendo razoável o seu deslocamento diário apenas para pernoitar naquele estabelecimento específico, com evidente perda de tempo e excessivos gastos com o transporte respectivo. Diante deste quadro, vem sendo admitida a prisão domiciliar com monitoramento eletrônico, tratando-se de política do juízo da VEP em harmonia com o executivo estadual e a anuência do próprio Ministério Público, sendo isolados os recla- 
mos do representante do parquet em casos específicos. (Agravo de execução penal 0041151-19.2015.8.19.0000. Rel. Des. Marcus Henrique Pinto Basilio, D.J. 22/09/2015).

O terceiro e último critério diz respeito a aspectos menos contextuais, podendo ser entendido mais como um posicionamento da Câmara em relação ao próprio instituto da monitoração e de sua eficácia como instrumento ressocializador, conforme se depreende da decisão que segue:

Insurgência do Ministério Público contra decisão que concedeu à agravada a progressão para o regime aberto, na modalidade prisão domiciliar, com monitoramento eletrônico. Pleito de cassação da decisão, por estar fora das hipóteses do rol taxativo do artigo 117, da lei $\mathrm{n}^{\circ}$. 7.210/84, que não merece prosperar. Jurisprudência iterativa dos tribunais superiores no sentido da possibilidade de concessão da prisão domiciliar excepcionalmente fora das hipóteses do referido dispositivo legal, por questões de política criminal, como no caso dos autos. As casas de albergados existentes em nosso estado, na maneira como hoje se apresentam, não se prestam à ressocialização do apenado buscada pela execução penal. No caso em tela, a prisão albergue domiciliar, com monitoramento eletrônico, viabilizará a reintegração da agravada ao meio social, que é a clara intenção da lei de execuções penais. Recurso a que se nega provimento. (Agravo de execução penal 0067957-91.2015.8.19.0000 Rel. Des. Luiz Zveiter, D.J. 15/12/2015).

Com perfil decisório bastante diferente da $1^{\text {a }}$ Câmara, a $2^{\text {a }}$ Câmara Criminal - responsável pelo julgamento de $11 \%$ dos casos observados - apresenta índice de deferimento de $77 \%$, contra $23 \%$ indeferimentos. Em sua maioria, as decisões desta Câmara não entram em discussões fáticas acerca do número de vagas, qualidade dos estabelecimentos etc., limitando-se a expor entendimento segundo o qual o art. 117 da LEP não comporta interpretação extensiva. É nesse sentido a decisão a seguir:

Com todas as vênias ao entendimento esposado pelo digno subscritor da decisão agravada, não compreendo suficientemente 
justificada a adoção da modalidade de prisão albergue domiciliar - medida excepcional, repita-se - no caso concreto, pois ausente qualquer menção à circunstância fática excepcional. A adoção do referido entendimento redunda, na verdade, na negativa de aplicação da lei, fazendo da exceção uma regra, tornando letra morta o que prevê o artigo 117 da Lei de Execuções Penais. Ademais, tanto nas razões recursais, como nas contrarrazões, admite-se a existência de vagas na casa de albergado existente na Capital, fato que, por si só, já afasta a possibilidade de qualquer interpretação extensiva e aplicação do artigo 117 da LEP, na hipótese.

(...) Assim, impossível ratificar-se a decisão agravada, uma vez que proferida ao arrepio da lei, fundamentada, na realização do Princípio da Isonomia que, com todas as vênias, não pode, in casu, sobrepor-se ao princípio da legalidade. Acrescente-se que, se o entendimento desta Corte é no sentido de que é inadequada a concessão de prisão albergue domiciliar com monitoramento eletrônico, com muito mais razão, apresenta-se inadequada a concessão do especial modelo, sem monitoramento eletrônico, uma vez que se reduz, ainda mais, a possibilidade de fiscalização do apenado. (Agravo de execução penal 0034033-89.2015.8.19.0000 - Rel. Des. José Muiños Pinheiro. D.J 05.12.2015).

Seguindo o padrão de decisão da $2^{\text {a }}$ Câmara, a $4^{\text {a }}$ Câmara Criminal julgou $15 \%$ dos casos observados, tendo deferido $97 \%$ dos requerimentos do MP, indeferindo apenas 3\%. Como na $2^{\text {a }}$ Câmara, as decisões analisadas não têm por hábito examinar as especificidades ou problemáticas do caso concreto, restringindo sua fundamentação ao entendimento daquele órgão colegiado a respeito dos limites de aplicabilidade do art. 117 da LEP, salientando em alguns momentos a questão do sentimento de impunidade e também da distância entre casa de albergado e local de residência/trabalho do apenado :

Decisão do Juiz da VEP que concedeu prisão albergue domiciliar ao agravado sem monitoramento. Recurso do MP pleiteando a cassação da decisão. Com razão o Ministério Público: Apenado não se enquadra em qualquer das hipóteses mencionadas no art. 117 da LEP. Enumeração das hipóteses em que o Juiz pode conceder a prisão domiciliar é taxativa, não permitindo ampliações, pois se trata de um benefício mais brando. 
(...) Concessão do PAD sem monitoramento gera forte sensação de impunidade na sociedade. (Agravo de execução penal 0048830-70.2015.8.19.0000. Rel. Des. Giselda Leitão. D.J. $15 / 12 / 2015)$.

(...) Ademais, o regime aberto, embora seja uma forma mais branda e progressiva da execução da pena, não é um prêmio e exige sacrifícios que longe estão de serem diferentes daqueles que são suportados diariamente pela infinita maioria dos brasileiros ordeiros, que se deslocam, por vezes, por várias horas, para desempenhar suas atividades laborativas. (Agravo de execução penal 0052932-38.2015.8.19.0000, Rel. Des. Antônio Eduardo Ferreira Duarte, D.J.10/11/2015).

Apresentando um entendimento diametralmente oposto àquele das duas últimas Câmaras citadas, na $5^{\text {a }}$ Câmara Criminal (responsável pelo julgamento de $13 \%$ dos casos observados) o Ministério Público teve todos os seus pedidos indeferidos. As razões de decidir dizem respeito em grande parte à própria natureza do art. 117 da LEP e mais especificamente ao cabimento da interpretação extensiva:

Em que pese a divergência doutrinária e jurisprudencial quanto à natureza jurídica do art. 117 da Lei de Execução Penal, que estabelece as hipóteses de prisão domiciliar, predomina no âmbito dos Tribunais Superiores e deste Egrégio Tribunal de Justiça o entendimento que admite a sua ampliação para abarcar outras hipóteses não previstas em lei. 2. A inércia estatal em dar cumprimento ao art. 95 da Lei de Execução Penal "que determina a manutenção de pelo menos uma Casa de Albergado em cada região", assim como a inexistência de vagas nestes estabelecimentos prisionais, ou sua oferta em condições insalubres e precárias, não podem acarretar óbice à reintegração do apenado, não se podendo admitir que a omissão estatal inviabilize a sua adequada ressocialização.

(...) Nesse contexto, agiu com acerto a douta magistrada de piso, adotando a única solução capaz de conciliar o direito do Estado de ver cumprida a pena imposta com o direito que assiste ao preso de usufruir da progressão de regime como lhe faculta a lei, inclusive sem monitoramento eletrônico, reservando-se as ex- 
cepcionais vagas disponíveis na Casa do Albergado às situações igualmente excepcionais. (Agravo de execução penal 003708071.2015.8.19.0000, Rel. Des. Paulo Baldez. DJ. 17/09/2015).

Já a $6^{\mathrm{a}}$ Câmara Criminal ( $9 \%$ do total de casos) apresenta índice de deferimento de $61 \%$ seguido de um índice de indeferimento de $39 \%$. Algumas dessas decisões expressam entendimentos bem contraditórios acerca do art. 117 da LEP, como ilustram as decisões a seguir. A primeira decisão é pelo deferimento do pleito do Ministério Público enquanto que a segunda mantém a decisão de $1^{\mathrm{a}}$ instância:

Agravo (artigo 197, da lei 7.210/84). Prisão domiciliar. O recolhimento do condenado em residência particular (prisão domiciliar) só é admissível nas taxativas hipóteses elencadas no artigo 117 , da lei de execução penal, nas quais o recorrido não se enquadra. Observo não constar da decisão hostilizada que essa medida decorria da inexistência de vaga em unidades prisionais compatíveis com o regime aberto. Ademais, não foi estabelecida a monitoração eletrônica prevista na lei 12.258/2010. Provimento do recurso, cassando-se a decisão guerreada. (Agravo de execução penal 0034047-73.2015.8.19.0000, Rel. Des. Fernando Antônio de Almeida, D.J. 22/09/2015).

A prisão albergue domiciliar, embora haja vagas nas casas do albergado para receber o ora agravado, melhor viabilizará a reintegração do mesmo ao meio social, que é exatamente a intenção da lei de execuções penais, não violando, desta forma, o artigo 117 da LEP, até porque a vaga só existe em razão da medida de adoção do PAD com monitoração eletrônica como regra para cumprimento da pena em regime aberto, pois de outra forma os estabelecimentos prisionais ainda estariam superlotados, sem condições de receber qualquer apenado.

(...) Dado parcial provimento ao recurso para determinar que a prisão domiciliar se faça sob monitoramento eletrônico, tão logo seja restabelecido o serviço. (Agravo de execução penal 003354889.2015.8.19.0000, Rel. Des. Paulo de Tarso, D.J. 21/07/2015).

A $7^{\text {a }}$ Câmara Criminal (responsável por $7 \%$ dos casos observados) apresenta exatamente os mesmos resultados da $5^{\text {a }}$ Câmara 
Criminal, tendo ela também indeferido todos os requerimentos feitos pelo Ministério Público. Apresenta argumentos semelhantes aos observados na $5^{\text {a }}$ Câmara Criminal, sustentando essencialmente a possibilidade de interpretação extensiva do art. 117 da LEP, bem como o caráter ressocializador da Prisão albergue domiciliar.

A despeito da excepcionalidade legal e em homenagem a mens legis da Lei de Execuções Penais, que tem como escopo maior a gradual e efetiva ressocialização e reinserção do apenado em seio social, a jurisprudência pátria tem admitido que em determinadas situações, notadamente em caso de inexistência de Casa do Albergado na Comarca de residência do apenado 'o que dificultaria sobremaneira sua referida inserção gradativa na sociedade' a concessão da prisão albergue domiciliar. Agravo desprovido. Unânime. (Agravo de execução penal 003304131.2015.8.19.0000, Rel. Des. Joaquim Domingos de Almeida Neto, D.J. 04/08/2015).

Por fim, os resultados da $8^{\mathrm{a}}$ Câmara Criminal (23\% dos casos julgados) se assemelham aos da $6^{\mathrm{a}}$ Câmara, ambas apresentando dois entendimentos antagônicos e, não obstante, bem sedimentados naqueles órgãos. De fato, a $8^{\mathrm{a}}$ Câmara deferiu $48 \%$ dos pedidos do MP, indeferindo $52 \%$ dos pleitos. Vejamos algumas dessas decisões ${ }^{21}$ :

O caso em comento não representa nenhuma das hipóteses de exceção ao disposto no artigo 117 da Lei de Execuções Penais, posto que o agravado é domiciliado no Município do Rio de Janeiro, onde há Casa de Albergado. A decisão do Magistrado a quo se embasou na "contumaz superlotação" dos referidos estabelecimentos prisionais, sem restar, concretamente, demonstrada a indisponibilidade de vagas.

(...) a concessão de prisão domiciliar ao apenado, fora das exceções previstas no artigo supracitado, fere o princípio da isonomia.

(...) Assim, não há razão, no caso dos autos, para que o agravado cumpra a pena em prisão albergue domiciliar, impondo-se

${ }^{21}$ As duas primeiras indeferindo, as duas últimas deferindo pleito do MP. 
a cassação da decisão impugnada. (Agravo de execução penal 0068030-63.2015.8.19.0000. Rel. Des. Claudio Tavares, D.J. 10.08.2015).

No caso dos autos, o agravado é morador do Jardim Carioca Ilha do Governador, nesta Cidade, não havendo empecilho que atrapalhe o seu recolhimento a Casa do Albergado para o cumprimento da prisão no regime aberto.

(...) Demonstrado nos autos que o apenado reside no Jardim Carioca - Ilha do Governador - Rio de Janeiro, e que existe casa de albergado na localidade, com disposição de vagas para o seu ingresso, não se vislumbra ser necessário o cumprimento de pena em lugar diverso. (Agravo de execução penal 0067867-83.2015.8.19.0000, Re. Des. Suely Magalhaes, D.J. 27/01/2016).

No caso dos autos, a apenada reside no município de São Gonçalo, ou seja, fora da Comarca da Capital, cidade em que há vagas em Casa de Albergado.

(...) Assim, constata-se inexistir óbice para que a mesma cumpra sua pena em regime aberto, na modalidade de prisão albergue domiciliar com monitoramento eletrônico, eis que inadmissível obrigá-la a deslocar-se para região distante de seu Município ou impor-lhe condições de regime mais severo, para o cumprimento da pena. (Agravo de execução penal 0063806-82.2015.8.19.0000, Rel. Des. Elizabete Alves de Aguiar D.J. 15/12/2015).

Conforme se verifica nos autos, o magistrado decidiu corretamente, a apenada é moradora do Município de Nova Iguaçu, distante das Cidades onde contem Casas de Albergado (Capital e em Niterói). A PAD monitorada acaba com o enorme distanciamento entre a forma de cumprimento das regras do regime aberto pelos apenados que residem em comarcas desprovidas de Casas de Albergado. Portanto, inexistindo Casa de Albergado no domicílio da apenada, é legítima a concessão de prisão domiciliar, porquanto vedada imposição de reprimenda em forma mais severa do que a devida. Agravo ministerial desprovido. (Agravo de execução penal 0063837-05.2015.8.19.0000, Rel. Des. Suely Magalhaes, D.J. 27/01/2016). 
A análise dos julgamentos proferidos pelas Câmaras Criminais do Tribunal de Justiça do Rio de Janeiro traz à tona uma problemática séria e recorrente no tocante à disparidade das decisões acerca da monitoração eletrônica. Falamos em termos de disparidade porque as decisões analisadas não se diferenciam em razão de eventuais particularidades ou diferenças dos casos e sim por refletirem entendimentos diferentes acerca do cabimento ou não da monitoração eletrônica. Dito de outra maneira, os dados de todos os procedimentos examinados são equivalentes, entretanto, seus desfechos são distintos em razão dos posicionamentos pessoais dos julgadores.

Essa heterogeneidade pode ser entendida em dois níveis. No primeiro nível, temos a disparidade interna nas Câmaras, ou seja, entendimentos opostos dentro de um mesmo órgão colegiado. Isso pôde ser observado sobretudo nas $6^{\mathrm{a}}$ e $8^{\mathrm{a}}$ Câmaras Criminais, por exemplo.

A mesma $6^{\mathrm{a}}$ Câmara Criminal possui uma decisão cassando a concessão de PAD porque não havia nos autos comprovação da falta de vagas em unidade de regime aberto, ao lado de outra que rejeitava o pedido de cassação da PAD arguindo que mesmo havendo vagas de unidade de regime aberto, a prisão albergue domiciliar deve ser mantida por viabilizar melhor a reintegração do apenado.

O debate na $8^{\text {a }}$ Câmara era voltado para a questão do local de moradia e da proximidade ou não de alguma unidade de cumprimento de pena em regime aberto. Assim é que, se um apenado morar em Nova Iguaçu ou São Gonçalo, ele pode permanecer em prisão albergue domiciliar, mas se morar na Ilha do Governador o caso muda de figura e ele terá que voltar para Casa de Albergado.

No segundo nível, podemos identificar a disparidade através da comparação das decisões proferidas por cada Câmara Criminal. O gráfico a seguir apresenta visualmente os dados expostos acima: 


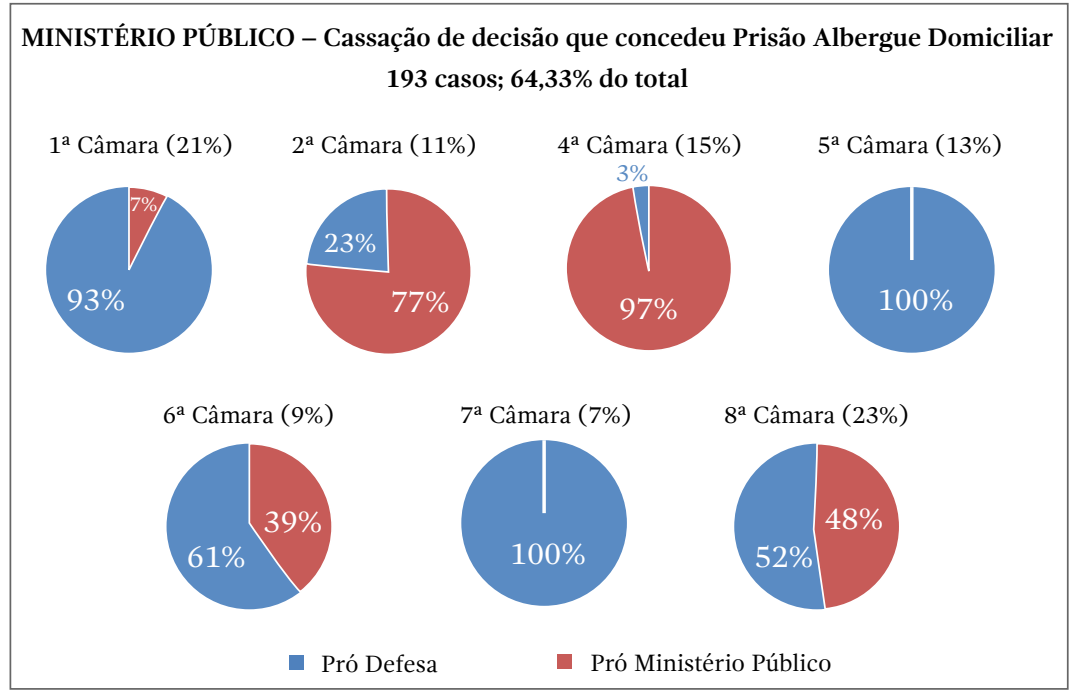

Gráfıco 4. Frequência total e relativa. Pedido de cassação da decisão de concedeu prisão albergue domiciliar.

Os dados apresentados acima revelam a ampla discrepância das decisões proferidas pelas Câmaras Criminais do Rio de Janeiro. Comparando os órgãos com distribuições de processos similares (11\% na frequência total), vemos que se o agravo de execução de um apenado for distribuído para a $7^{\mathrm{a}}$ Câmara Criminal, não há chance da decisão de $1^{\mathrm{a}}$ instância ser revertida, mas se referido recurso for para a $2^{\text {a }}$ Câmara, há 77\% de chance de ele perder o direito à prisão albergue domiciliar, sendo obrigado a cumprir restante da pena em Casa de Albergado. Situação similar ocorre se compararmos a $5^{\mathrm{a}}$ e a $4^{\mathrm{a}}$ Câmara Criminal. Sendo o agravo distribuído para a $5^{\text {a }}$ Câmara, é certo que o apenado segue em PAD, mas se o mesmo recurso cair da $4^{\text {a }}$ Câmara, é praticamente certo que ele terá que voltar para Casa de Albergado (97\% de deferimento do pedido de cassação de PAD).

Conclui-se, portanto, que há uma relevante disparidade na forma de decidir entre as Câmaras, que se torna ainda mais expressiva quando se considera os volumes processuais similares e a uniformidade entre os pedidos e as subsequentes decisões conflitantes.

A heterogeneidade presente nos julgamentos examinados viola os princípios da igualdade e da segurança jurídica - previstos no art. $5^{\circ}$, 
caput, da Constituição da República de 1988 - gerando graves implicações concretas, tanto no campo do Direito quanto na vida dos jurisdicionados, posto que imprevisibilidade das decisões judiciais fortalece a insegurança jurídica, enfraquecendo desta forma o próprio regime democrático e ofendendo os princípios da dignidade humana, da valorização da cidadania e da estabilidade das instituições (Delgado, 2011, p. 4).

\section{ConsideraçõEs finaIS}

Por meio da análise das decisões proferidas ao longo de um ano (2015) pelas Câmaras Criminais do Tribunal de Justiça do Rio de Janeiro, o artigo analisou o padrão decisional desses órgãos colegiados no que tange a monitoração eletrônica, buscando conhecer de que forma esta nova tecnologia esta sendo compreendida e aplicada pelos julgadores.

Mostramos que a monitoração eletrônica é usada de forma bastante limitada como alternativa à prisão cautelar, sendo empregada predominantemente na esfera da execução penal. Nesse sentido, percebe-se a subutilização do potencial desencarcerador dessa tecnologia, funcionando essencialmente como instrumento de controle disciplinar do sentenciado.

Tendo em vista a imensa população carcerária brasileira e o altíssimo percentual de presos provisórios, torna-se urgente que os tribunais e atores penais em geral tomem conhecimento e saibam lidar adequadamente com a ferramenta da monitoração eletrônica.

Mostramos, também, a problemática ligada ao padrão de decisão do Tribunal de Justiça no que diz respeito à monitoração eletrônica, revelando importante disparidade presente nas decisões desta corte e a consequente imprevisibilidade das decisões judiciais. Nesse sentido, e em respeito aos princípios constitucionais da isonomia e da segurança jurídica, torna-se urgente uma uniformização do entendimento do Tribunal de Justiça no que diz respeito à interpretação extensiva do art. 117 da Lei de Execuções Penais, bem como às hipóteses cabimento do instituto da Prisão albergue domiciliar como alternativa ao cumprimento de pena em unidade de regime aberto. 


\section{Biblografia}

CAMPELlO, R. A implementação do monitoramento eletrônico no Brasil. Parecer elaborado no âmbito do Programa Justiça Sem Muros do Instituto Terra, Trabalho e Cidadania, 2015. Disponível em <http://ittc.org.br/wp-content/ uploads/2016/03/Monitoracao-eletronica.pdf>. Acesso em: 06 mar. 2017.

CAMPELlO, R. Política, direitos e novos controles punitivos. Dissertação de Mestrado. Pontifícia Universidade Católica de São Paulo, São Paulo, 2013.

CORREAA JUNIOR, A. Monitoramento eletrônico de penas e alternativas penais. Tese de doutorado em direito. Faculdade de Direito da Universidade de São Paulo - USP, São Paulo, 2012. https://doi.org/10.11606/t.2.2012.tde-20062013132709

DELGADO, J. A. A Imprevisibilidade das Decisões Judiciárias e seus Reflexos na Segurança Jurídica, 2011. Disponível em <http://bdjur.stj.jus.br/jspui/ handle/2011/74120>. Acesso em: 06 mar. 2017.

DUARTE JÚNIOR, A.P.; MENEZES, M. Monitoramento Eletrônico: Uma Alternativa Para Crise Vivida Pelo Sistema Penitenciário Brasileiro. Revista FSA, vol. 12, n. 4, p. 68-86, jul. 2015. https://doi.org/10.12819/2015.12.4.5

FONSECA, A.L. O monitoramento eletrônico e sua utilização como meio minimizador da dessocialização decorrente da prisão. Porto Alegre: Nuria Fabris, 2012

IGLESIA RION, M.A; PARENTE, J.A. La pena de localización permanente y su seguimiento como medios de control electrónico. México, 2006. Biblioteca Virtual del instituto de Investigaciones Jurídicas de la Universidad Nacional Autónoma do México. Disponível em: <http://www.corteidh.or.cr/tablas/ R08047-1.pdf>. Acesso em: 06 mar. 2017.

JAPIASSU, C.A e MACEDO, C.M. O Brasil e o Monitoramento Eletrônico. In: Monitoramento Eletrônico: Uma Alternativa à Prisão? Experiências Internacionais e Perspectivas no Brasil. Brasília: Conselho Nacional de Política Criminal e Penitenciária. Ministério da Justiça, 2008.

KARAM, M.L. Monitoramento eletrônico: a sociedade do controle. Boletim IBCCRIM, São Paulo, v. 14, n. 170, p. 4-5., jan. 2007.

MARIATH, C. A. Monitoramento eletrônico: liberdade vigiada. Observatório de Segurança, 2008. Disponível em: http://observatoriodeseguranca.org/files/ Monitoramento\%20Eletr\%C3\%B4nicoCarlosMariath.pdf. Acesso em: 06 mar. 2017. 
MECANISMO ESTADUAL DE PREVENÇÃO E COMBATE À TORTURA DO RIO DE JANEIRO. Quando a liberdade é exceção: A situação das pessoas presas sem condenação no Rio de Janeiro, 2016. Disponível em: <http://www.global.org. br/wp-content/uploads/2016/09/quando-a-liberdade-e-excecao.pdf $>$. Acesso em: 06 mar 2017.

MECANISMO ESTADUAL DE PREVENÇÃO E COMBATE À TORTURA DO RIO DE JANEIRO. Mulheres, Meninas e Privação de Liberdade no Rio de Janeiro, 2016. Disponível em: <http://piaui.folha.uol.com.br/lupa/wp-content/ uploads/sites/24/2016/03/Mulheres-Meninas-e-Priva\%C3\%A7\%C3\%A3o-deLiberdade-no-Rio-de-Janeiro-010316.pdf>. Acesso em: 06 mar 2017.

MECANISMO ESTADUAL DE PREVENÇÃO E COMBATE À TORTURA DO RIO DE JANEIRO. Análise da progressão de regime de cumprimento de pena no sistema penitenciário do Rio de Janeiro, 2013. Disponível em: <http://ddh.org. br/wp-content/uploads/2013/12/Relat\%C3\%B3rio-Porta-de-Sa\%C3\%ADdavers\%C3\%A3o-final2-11.pdf>. Acesso em: 06 mar 2017.

MINISTÉRIO DA JUSTIÇA. A implementação da política de monitoração eletrônica de pessoas no Brasil - Análise crítica do uso da monitoração eletrônica de pessoas no cumprimento de pena e na aplicação de medidas cautelares diversas da prisão e medidas protetivas de urgência, 2015. Disponível em: $\quad<$ http://www.justica.gov.br/noticias/mj-divulga-primeiro-diagnosticonacional-sobre-monitoracao-eletronica-de-pessoas>. Acesso em: 06 mar 2017.

MINISTÉRIO DA JUSTIÇA. Levantamento Nacional de Informações Penitenciárias INFOPEN - Departamento Penitenciário Nacional, 2014. Disponível em: <http://www.justica.gov.br/seus-direitos/politica-penal/ infopen_dez14.pdf>. Acesso em: 06 mar 2017.

MINISTÉRIO DA JUSTIÇA. Monitoramento eletrônico: uma alternativa à prisão? Experiências internacionais e pesquisas no Brasil. Brasília: Conselho Nacional de Política Criminal e Penitenciária, 2008.

MINISTÉRIO DA JUSTIÇA e INSTITUTO DE PESQUISA ECONÔMICA APLICADA. Excesso de Prisão Provisória no Brasil: um estudo empírico sobre a duração da prisão nos crimes de furto, roubo e tráfico. Série Pensando o Direito, $\mathrm{n}^{\circ}$ 54, Brasília, DF, 2015.

OLIVEIRA, J.; GHIRINGHELLI, R. O monitoramento eletrônico de apenados no Brasil. Revista Brasileira de Segurança Pública, São Paulo, Ano 5, Edição 9, pp. 100-120, 2011.

PINTO, M. Prisão domiciliar gera controvérsia e divide o TJ-RJ. Conjur, 2014. Disponível em: <http://www.conjur.com.br/2014-jan-27/aplicacao-prisaodomiciliar-gera-controversia-divide-tj-rj>. Acesso em: 06 mar 2017. 


\section{DADOS DO PROCESSO EDITORIAL}

(http://www.ibraspp.com.br/revista/index.php/RBDPP/about/editorialPolicies)

- Recebido em: 30/03/2017

- Controle preliminar e verificação de plágio: 30/03/2017

- Avaliação 1: 03/04/2017

- Avaliação 2: 07/04/2017

- Avaliação 3: 15/04/2017

- Decisão editorial preliminar: 15/04/2017

- Retorno rodada de correções 1: 29/04/2017

- Decisão editorial preliminar 2: 30/04/2017

- Retorno rodada de correções 2: 02/05/2017

- Decisão editorial final: 02/05/2017

\section{Equipe editorial envolvida}

- Editor-chefe: 1 (VGV)

- Revisores: 3

\section{COMO CITAR ESTE ARTIGO:}

BOTTINO, Thiago; PRATES, Fernanda. Notas sobre a política de monitoração eletrônica no estado do Rio de Janeiro. Revista Brasileira de Direito Processual Penal, Porto Alegre, vol. 3, n. 2, p. 719-746, mai./ago. 2017. https://doi.org/10.22197/rbdpp.v3i2.68

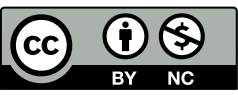

Esta obra está licenciada com uma Licença Creative Commons Atribuição-NãoComercial 4.0 Internacional. 